\title{
ON TWO NORTH AMERICAN PHILOTARSIDS (PSOCOPTERA) ${ }^{1}$

\author{
By EdWARD L. MOCKFoRd \\ Indianapolis, Indiana
}

\begin{abstract}
Until now, but a single species of Philotarsidae has been known from North America. ${ }^{2}$ While collecting at Port Townsend, Washington, I found a second species, in the genus Philotarsus, apparently new. Unfortunately, good specific characters of only one species, the European genotype, are available to me for comparison, but the figures given here should be adequate for separation of the new species. Described early from eastern United States was Philotarsus maculosus (Aaron). This species cannot fit in Philotarsus as restricted by Badonnel (1943), but remains in this family. I therefore propose a new genus for it named in honor of its describer.
\end{abstract}

\section{Genus Aaroniella n. gen.}

Differs from Philotarsus in that (1) $\mathrm{R}_{\mathrm{s}}$ in hind wing is ciliated, though sparsely, for its entire length beyond its separation from $\mathrm{M}$, (2) sense tubercles of male paraprocts round; elongate in Philotarsus, (3) phallic frame of approximately even thickness all around, not dilated anteriorly, and lacking a secondary sclerite posteriorly, (4) lateral gonapophyses of female triangular, (5) pigmented areas of subgenital plate wide, (6) antennal color pattern: each flagellar segment is white at its apex which contrasts sharply with the darker remainder, (7) many of the hairs on the veins of the fore wing with brown spots at their bases. Also of probable generic value is the peculiar tip of the maxillary pick (see pl. 9, fig. 5), and the well-developed

${ }^{1}$ Published with a grant from the Museum of Comparative Zoology at Harvard College.

2 When preparing this paper, I overlooked a paper by Dr. A. B. Gurney (Jour. Wash. Acad. Sci., 39: 56-65, 1949) in which records of Philotarsus flaviceps (Ste.) from Mount Desert Island, Maine, are cited. 
gonopore plate, apparently absent or at least not sclerotized in Philotarsus.

Genotype: Elipsocus maculosus Aaron Aaroniella maculosa (Aaron)

(Pl. 8, Figs. 1, 4, 5, 7; Pl. 9, Figs. 3, 4, 5, 6, 8, 9)

Elipsocus maculosus Aaron (1883, p. 40, pl. 9, fig. 8)

Philotarsus maculosus (Aaron) Chapman \& Nadler (1928)

No measurements are given in the original description. The following are for a typical male and female: Fore wing: o $3.36 \mathrm{~mm}$., o $2.85 \mathrm{~mm}$. Total body length: ô 2.85 mm., o (gravid) $3.24 \mathrm{~mm}$. Antennal length: of 2.49 \& $2.55 \mathrm{~mm}$., o $2.10 \mathrm{~mm}$.

The figure of the fore wing in the original description is not very detailed and has at least one inaccuracy - vein An is shown with hair, Ax hairless, whereas actually it is just the reverse. I here include figures of both wings. The male shows a very minute spur vein on the posterior edge of the pterostigma; this is lacking in the female. Male ocellar interval dark, that of female pale. Both sexes with rather numerous long hairs posteriorly on vertex and a fuscous lateral band starting just behind head, widening on the meso- and metapleura, narrowing again on the abdomen, and ending at the sclerotized terminal segments. Male genitalia (pl. 8, fig. 5; pl. 9, fig. 4) : phallic frame anteriorly rounded and narrow, slightly wider on sides. A complex group of 'accessory sclerotizations' lies just above the frame and is easily visible between its sides. Aedeagal arch tuberculate. Hypandrium rather weakly sclerotized, hairy. Epiproct (pl. 8, fig. 4) emarginate posteriorly. Female genitalia (pl. 8, fig. 7; pl. 9, figs. 3, 8, 9) : lateral gonapophyses triangular, hairy. Subgenital plate with wide pigmented areas separated in the middle; apical half sclerotized, and a small separate sclerite at extreme apex. Gonopore plate large and well sclerotized.

I have given (Mockford-in press) some biological observations and Indiana records of this species. Late-instar nymphs have numerous gland hairs on abdominal tergites and wing pads, but very few on head, thorax, and legs where there are numerous tapering hairs. 
Other species of Aaroniella

Mr. J. V. Pearman has very kindly sent me drawings of two other species belonging in this group: (1) of a $\hat{o}$ of an undescribed species in his collection; this agrees with the genotype in all bisexual and male characters listed in the generic diagnosis, (2) copies of drawings of Philotarsus badonelli Danks (1950). This is described from a female and agrees with the genotype in all female characters listed in the generic diagnosis plus (7). The antennae are not figured. In addition we suspect several other known species of belonging here.

\section{Philotarsus Kolbe, 1880}

In addition to the characters given by Badonnel $(1943: 70)$ it would appear that the females of this genus always have the pigmentation of the subgenital plate in the form of a pair of rather slender converging arms. Several figures of the genotype, $P$. flaviceps (Ste.) are given by Badonnel (op. cit.:71). These plus a drawing of the phallic frame sent to me by Mr. Pearman were used for comparison with the following species.

Philotarsus kwakiutl n. sp.

(Pl. 8, Figs. 2, 3, 6, 8; Pl. 9, Figs. 1, 2, 7)

Measurements of typical male and female: Fore wing: o $3.27 \mathrm{~mm}$., o $3.24 \mathrm{~mm}$. Total body length: o 1.86 mm., of $2.58 \mathrm{~mm}$. Antennal length : of $2.91 \mathrm{~mm}$., o $1.89 \mathrm{~mm}$.

Near the genotype, differing in that (1) apex of fore wing in both sexes is more prolonged, (2) areola postica is slightly longer and lower, (3) pigmented area of subgenital plate (pl. 9, fig. 1) more u- than v-shaped, (4) apical sclerite of subgenital plate shorter and wider, (5) tubercle of dorsal gonapophysis proportionately larger, (6) phallic frame (pl. 8, fig. 6), especially the anterior, basal portion long and drawn out.

\section{Explanation of Plate 8}

Fig. 1, Aaroniella maculosa (Aaron), $\hat{o}$, fore and hind wings. Fig. 4, the same, $\hat{\delta}$, epiproct. Fig. 5 , the same, $\hat{\delta}$, phallic frame. Fig 7 , the same, + , gonopore plate. Fig. 2, Philotarsus kwakiutl n. sp., $\hat{o}$, epiproct. Fig. 3, the same, $\hat{o}$, fore wing. Fig. 6, the same, of, phallic frame. Fig. 8, the same, $\hat{o}$, paraproct. 

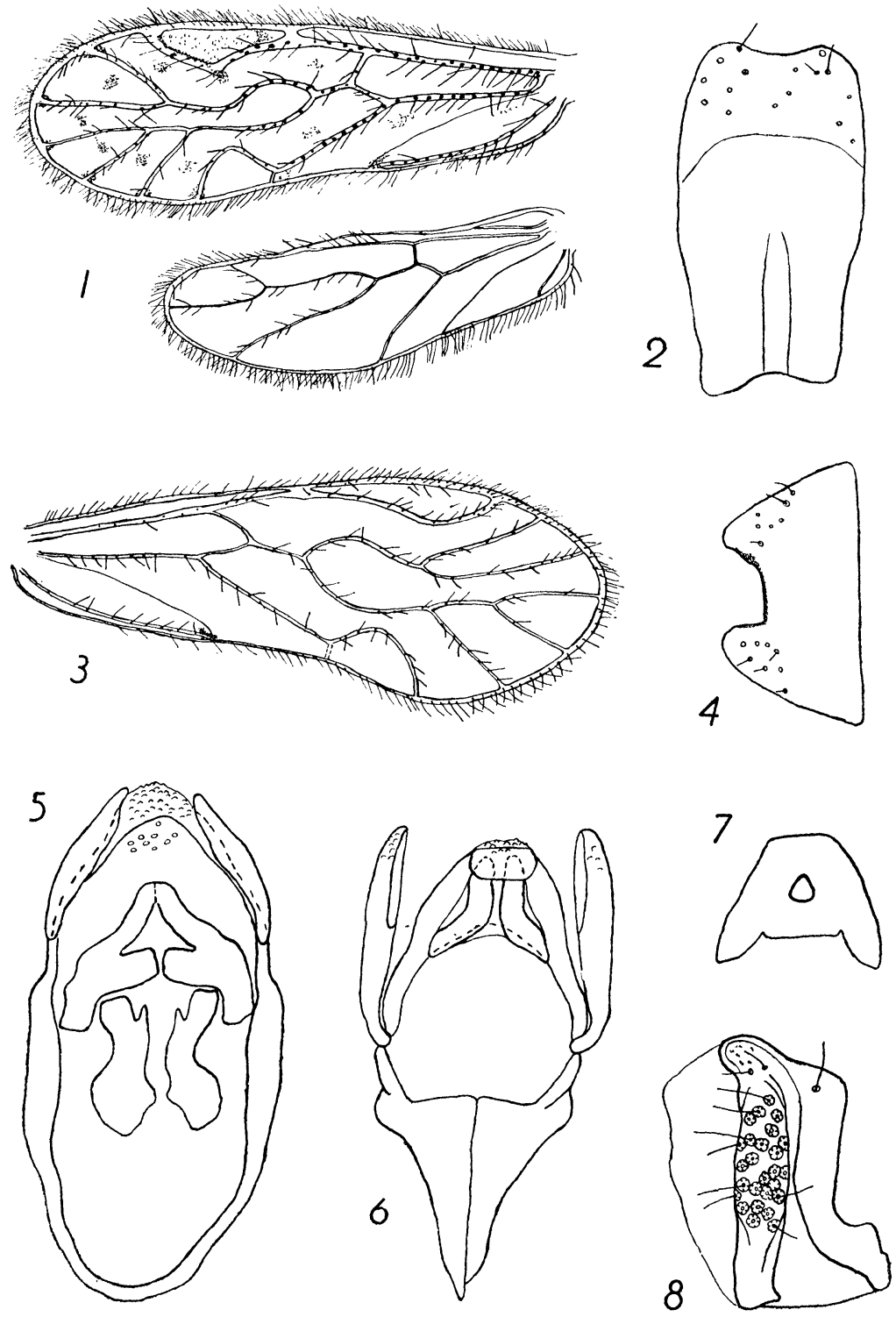

Mockford - PhILOTARSIDS 
Coloration: sexes similar. Clypeus with brown lineations separated into two groups by a pale line down the middle. They converge in the lower half forming a median band. Vertex with a band of brown spots along the epicranial suture and a group of brown spots just mesad each eye. Ocellar intervals pale. Frons with a posteriorly pointing v-shaped mark in middle. Labrum, antennae, and apical two segments of maxillary palpi brown. Mesonotal lobes: anterior with a pair of brown spots in front; laterals each with a brown band, but all these marks separated by wide pale areas. Fore wing (pl. 8, fig. 3) marked much as in genotype, but markings usually very obscure or absent. Hind wings unmarked. Abdominal tergites irregularly marked with light purplish brown, heaviest on sides.

Holotype of : Port Townsend, Washington, June 29, 1948, ex foliage of Thuja plicata, in author's collection. Allotype o : same data as for holotype. Paratypes: Port Townsend, Washington: $8 \hat{\delta}, 7$ 옹 same data as for holotype. 1 \% , July 5, 1948, ex foliage of Thuja plicata. 1 \&, 2 \%, July 6 , 1948, on dead, lichen-covered laurel twigs. Of these, 23 , 2 o will be placed in the K. M. Sommerman collection, and $1 \hat{\delta}, 1$ if will be placed in the Museum of Comparative Zoology, Cambridge, Mass.

Aanon, S. Frank

Literature Cited

1883. Description of New Psocidae in the Collection of the American Entomological Society. Trans. Am. Ent. Soc. 11:37-40, pl. IX.

BADONNEL, A.

1943. Faune de France: Psocoptères. pp. 70, 71. Paul Lechevalier, Paris. Chapman, P. J. and A. M. Nadler in Leonard, M. D.

1928. A list of the Insects of New York. (Corrodentia p. 62). Memoir 101, Cornell University Agricultural Experiment Station.

DANKS, LYDIA

1950. Novyi vid senoeda. Pscoptères-Philotarsus badonelli Danks sp.

n. $q$. Gos. Muzei Prirody Riga LSSR, Coobshchenie No. 1.

EXPlanation of Plate 9

Fig. 1, Philotarsus kwakiutl n. sp., $\&$, subgenital plate. Fig 2, the same. $\delta$, hypandrium. Fig. 7, the same, $o$, gonapophyses. Fig. 3. Aaroniella maculosa (Aaron), $o$, subgential plate. Fig. 4, the same, $\delta$, hypandrium. Fig. 5, the same, $\delta$, maxillary pick. Fig. 6, the same, $j$, antenna. Fig. 8, the same, o, lateral gonapophysis. Fig. 9, the same, o, dorsal and ventral gonapophyses. 

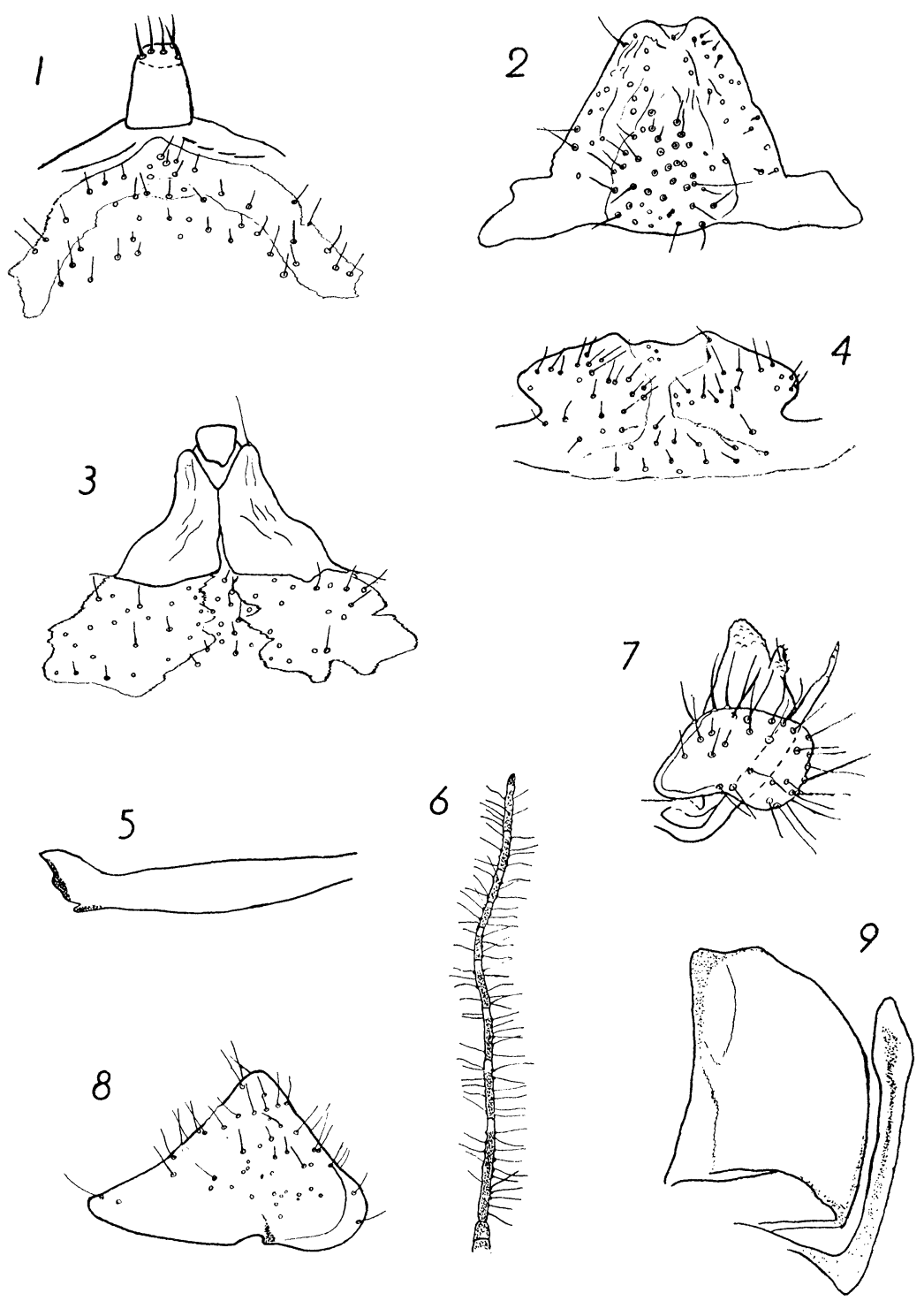

MOCKFORD - PhILOtARSIDS 

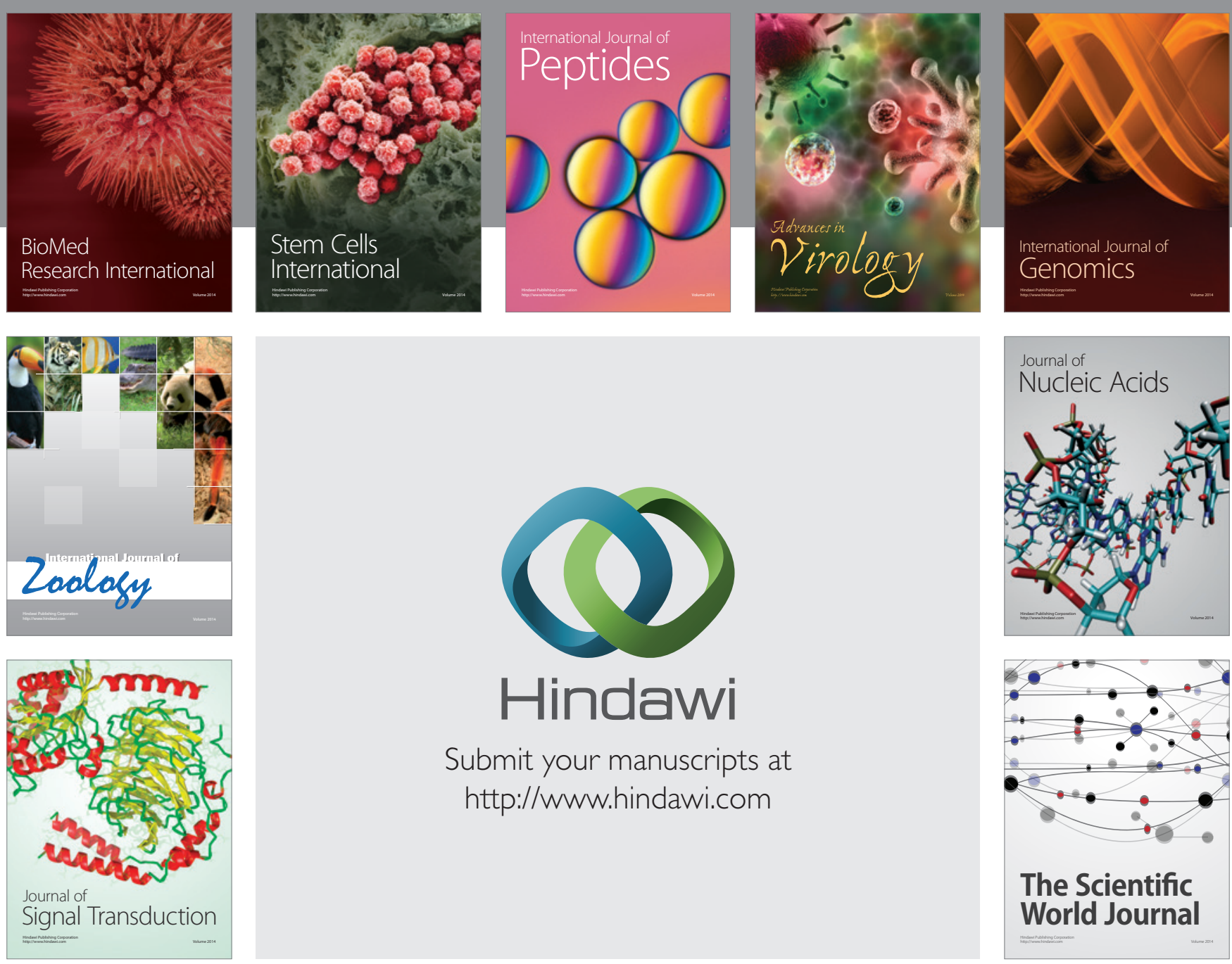

Submit your manuscripts at

http://www.hindawi.com
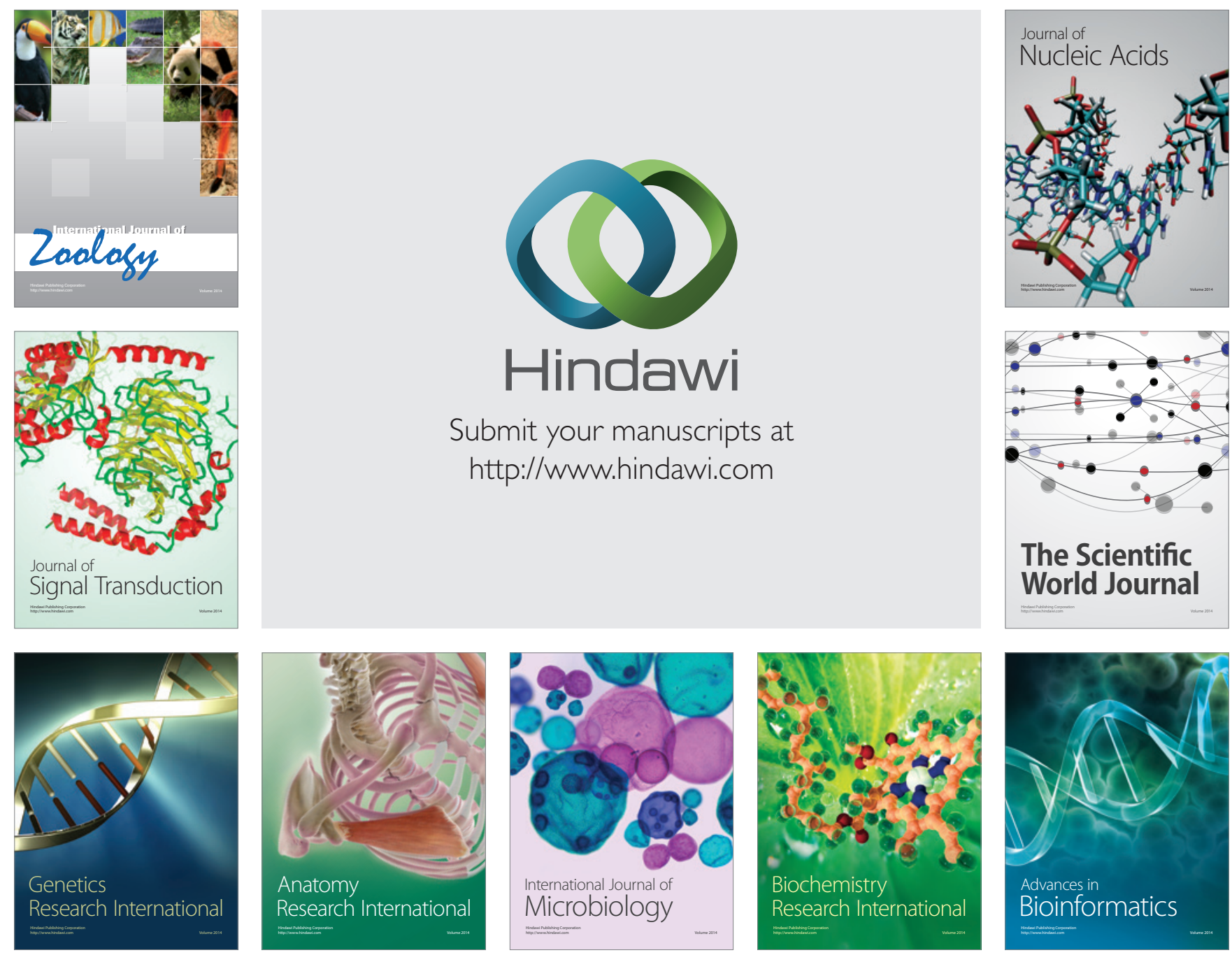

The Scientific World Journal
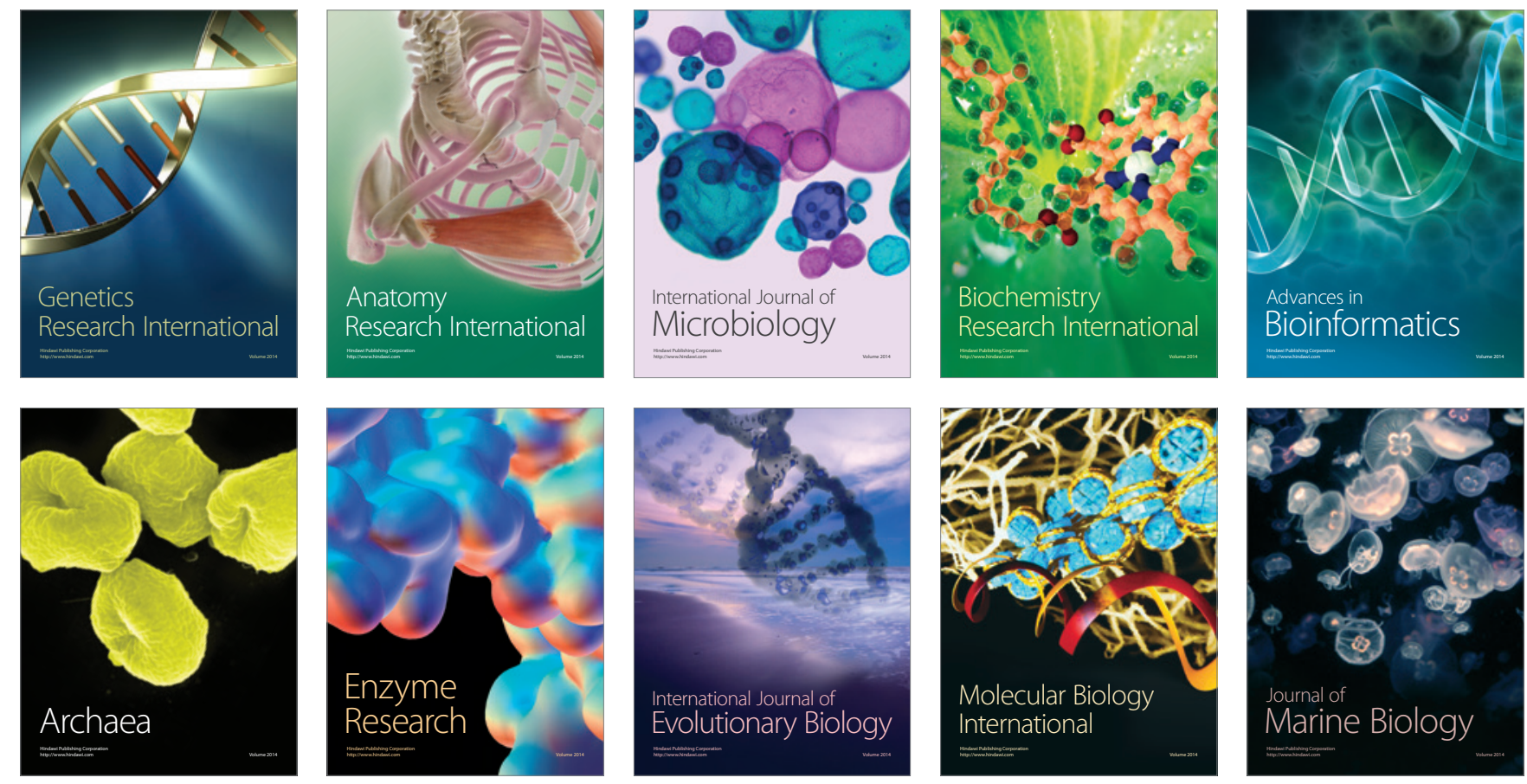